\title{
Chitinase Inhibitor Allosamidin Is a Signal Molecule for Chitinase Production in Its Producing Streptomyces
}

\author{
I. Analysis of the Chitinase Whose Production Is Promoted by \\ Allosamidin and Growth Accelerating Activity of Allosamidin
}

\author{
Shigeo Suzuki, ${ }^{\dagger}$ Eiyu Nakanishi, ${ }^{\dagger}$ Tsuyoshi Ohira, Ryu Kawachi, Hiromichi Nagasawa, \\ Shohei Sakuda
}

Received: May 25, 2006 / Accepted: July 18, 2006

(C) Japan Antibiotics Research Association

\begin{abstract}
Allosamidin, a typical secondary metabolite of Streptomyces, has been known as a chitinase inhibitor. We found that allosamidin can dramatically promote chitinase production and growth of its producer, Streptomyces sp. AJ9463, in a chitin medium at a few hundred nM. Allosamidin promoted production of the main chitinase detected in the culture filtrate and the chitin-hydrolytic activity of the chitinase was not inhibited by allosamidin at the concentration. The gene encoding the chitinase showed that it is a family 18 chitinase and it was revealed that two genes encoding proteins constructing two-component regulatory system were present at $5^{\prime}$-upstream region of the chitinase gene. Allosamidin is located in the microbial mycelia cultured in a medium without chitin, but it was released from the mycelia by responding to chitin. These results show that allosamidin acts as a key signal molecule for chitinase production in its producing strain, which may be useful for its growth in chitin-rich environment.
\end{abstract}

Keywords allosamidin, chitinase, Streptomyces, twocomponent regulatory system, signal molecule

S. Sakuda (Corresponding author), S. Suzuki, E. Nakanishi, T. Ohira, R. Kawachi, H. Nagasawa: Department of Applied Biological Chemistry, The University of Tokyo, Bunkyo-ku, Tokyo 113-8657, Japan, E-mail: asakuda@mail.ecc.u-tokyo.ac.jp

$\dagger$ These authors contributed equally to this work.

\section{Introduction}

Allosamidin is a typical secondary metabolite of Streptomyces without antibiotic activity [1]. It has a unique pseudotrisaccharide structure mimic to chitin [2] and inhibits all family 18 chitinases, which hydrolyze chitin and are widely present in nature [3]. Allosamidin has been used to investigate the physiological role of chitinases involved not only in chitin-containing organisms, but also in nonchitin-containing ones. In the former case, it inhibits cell separation in yeast [4], transmission of the malaria parasite [5] and insect molting [1]. In the latter case, inhibition of acidic mammalian chitinase by allosamidin causes a decrease in asthmatic Th2 inflammation [6].

With respect to allosamidin and its producer, we found a phenomenon that chitinase production in a chitin medium by the producer was activated by addition of allosamidin exogenously [7]. This seems to indicate that allosamidin has a physiological role in its producing Streptomyces because chitinase production is very important for the bacterial growth in soil where chitin originated mainly from insect cuticle and fungal cell walls is a major nutrient source. In this report, we will provide strong evidence to prove this hypothesis by describing detailed allosamidin's effects on chitinase production and growth of its producer and identification of the chitinase whose production was promoted by allosamidin as well as a novel phenomenon of allosamidin release from the mycelia of its producing microbe by responding to chitin. 


\section{Materials and Methods}

\section{Culture}

Streptomyces sp. AJ9463, an allosamidin producer [8], was maintained on a Bennet agar medium consisting of glucose $1 \%$, peptone $0.2 \%$, meat extract $0.1 \%$, and yeast extract $0.1 \%, \mathrm{pH} 7.2$, at $30^{\circ} \mathrm{C}$ and subcultured at about monthly intervals. Spores of the strain were inoculated into a Bennet medium $(100 \mathrm{ml})$ in a $500-\mathrm{ml}$ Erlenmeyer flask, and the flask was incubated at $30^{\circ} \mathrm{C}$ and $150 \mathrm{rpm}$ on a rotary shaker for 46 hours. This preculture was used for all main cultures in this study. In the experiments with a chitin medium which consists of colloidal chitin $0.2 \%, \mathrm{KCl} 0.05 \%$, $\mathrm{K}_{2} \mathrm{HPO}_{4} \quad 0.1 \%, \mathrm{MgSO}_{4} \cdot 7 \mathrm{H}_{2} \mathrm{O} \quad 0.05 \%$ and $\mathrm{FeSO}_{4} \cdot 7 \mathrm{H}_{2} \mathrm{O}$ $0.001 \%,\left(\mathrm{NH}_{4}\right)_{2} \mathrm{SO}_{4} 0.2 \%, \mathrm{pH} 7.2$, the preculture $(1.4 \mathrm{ml})$ was transferred into the chitin medium $(70 \mathrm{ml})$ in a $500-\mathrm{ml}$ Erlenmeyer flask, and the flask was incubated at $30^{\circ} \mathrm{C}$ and $120 \mathrm{rpm}$ on a rotary shaker. We previously used slightly different culture conditions from those used in this study for the main culture of strain AJ9463 in the chitin medium, in which culture was done in a 500-ml Sakaguchi flask at $120 \mathrm{rpm}$ instead of a $500-\mathrm{ml}$ Erlenmeyer flask at $150 \mathrm{rpm}$. Analysis of the $N$-terminal amino acid sequence of $65 \mathrm{kDa}$ protein was done with the culture filtrate obtained under this previously used culture condition. Allosamidin was dissolved in $0.1 \mathrm{M}$ acetic acid, and each solution after being passed through a $0.25 \mu \mathrm{m}$ sterile filter before use was added to the chitin medium or an inorganic salt solution at the beginning of culture.

\section{Chitinase Assay}

Chitinase assay was performed using 4-methylumbelliferyl$N, N^{\prime}, N^{\prime \prime}$-triacetyl chitotrioside [4MU-(GlcNAc) 3 ] (SigmaAldrich) as a substrate according to the method of Kuranda et al. [9]. A solution of $25 \mu \mathrm{M} 4 \mathrm{MU}-(\mathrm{GlcNAc})_{3}$ in $N, N-$ dimethylformamide was diluted five hundreds times with distilled water, and the resulting solution $(40 \mu \mathrm{l})$ was added to the mixture of the culture filtrate $(0.5,2$ or $4 \mu 1)$ in each experiment and the $50 \mathrm{mM}$ citric acid $-50 \mathrm{mM} \mathrm{Na}_{2} \mathrm{HPO}_{4}$ buffer ( $\mathrm{pH}$ 5.0) $(100 \mu \mathrm{l})$. After incubating the solution mixture at $28.5^{\circ} \mathrm{C}$ for 60 minutes, the reaction was stopped by addition of $1.0 \mathrm{M}$ glycine $-\mathrm{NaOH}$ buffer $(\mathrm{pH} 10.5$ ) $(2.5 \mathrm{ml})$, and the liberated 4-methylumbelliferone was measured with a fluorescence spectrometer (excitation at $360 \mathrm{~nm}$, emission at $450 \mathrm{~nm}$ ). The value of fluorescence strength was used for calibration of relative chitinase activity.

\section{Activity Staining}

The culture supernatant $(10 \mathrm{ml})$ in each experiment was concentrated by ultrafiltration (10,000 cut membrane, AMICON) to $4 \mathrm{ml}$. Acetone $(12 \mathrm{ml})$ was added to the concentrated solution to afford a precipitate. The precipitate was collected by centrifugation $(7,000 \mathrm{~g}, 30$ minutes) and dissolved in distilled water $(30 \mu \mathrm{l})$, followed by mixing with the electrophoresis sample buffer $(30 \mu l)$. After being left overnight at room temperature, the mixture was subjected to SDS-polyacrylamide gel electrophoresis (SDS-PAGE) under non-reducing conditions. After SDSPAGE, the gel was washed with $0.1 \mathrm{M} \mathrm{AcONa-AcOH}$ buffer ( $\mathrm{pH} \mathrm{5.0)}$ ) for 5 minutes and layered over the gel containing glycolchitin $(0.01 \%)$ and polyacrylamide gel (7.5\%) with or without allosamidin to transfer the proteins in the lower gel into the upper gel. The gels were left in $0.15 \mathrm{M} \mathrm{AcONa}-\mathrm{AcOH}$ buffer ( $\mathrm{pH} 5.0$ ) with or without allosamidin at $37^{\circ} \mathrm{C}$ for 180 minutes to allow an enzyme reaction by changing the buffer solution at 60 minutes intervals. The upper gel was stained by $0.01 \%$ fluorescent brightener 28 (Calcoflour, Sigma-Aldrich) in $0.1 \mathrm{M}$ Tris$\mathrm{HCl}(\mathrm{pH} 8.8$ ) buffer for 5 minutes at room temperature and washed overnight in water. The chitinase lytic bands on the gel were detected by a UV transilluminator.

\section{Detection of Growth-promoting Activity of Allosamidin}

Chitin contained in the culture was stained by $0.0005 \%$ fluorescent brightener 28 (Calcoflour, Sigma-Aldrich) and observed under a fluorescence microscope. The amount of ATP in each culture was measured by a luciferin-luciferasebased bioluminescence assay with a Lucifer LU plus kit (Kikkoman Co.) according to its protocol. Luminescence was measured by a luminometer (Luminescencer-JNR AB2100, ATTO).

\section{Chitinase Purification and Protein Sequencing}

The preculture $(1.4 \mathrm{ml})$ of strain AJ9463 prepared as described above was transferred into the chitin medium (70 ml) with allosamidin $(2 \mu \mathrm{M})$ in a $500-\mathrm{ml}$ Sakaguchi flask, and the flask was incubated at $30^{\circ} \mathrm{C}$ and $120 \mathrm{rpm}$ on a rotary shaker for 24 hours. The culture filtrate (2.8 liters) was concentrated to $15 \mathrm{ml}$ by ultrafiltration $(10,000$ cut membrane, AMICON) and added leupeptin $(3 \mathrm{mg})$. This solution was put on a column which was packed with chitin powder (5 g, Wako) and preequilibrated with $50 \mathrm{mM}$ Tris$\mathrm{HCl}$ buffer ( $\mathrm{pH}$ 9.0), and the column was left for 120 minutes at room temperature. After washing the column with $50 \mathrm{mM}$ Tris- $\mathrm{HCl}$ buffer $(\mathrm{pH} 9.0)(30 \mathrm{ml})$, crude chitinases were eluted with $0.1 \mathrm{M}$ acetic acid $(90 \mathrm{ml})$. The $0.1 \mathrm{M}$ acetic acid eluate was concentrated by ultrafiltration and desalted by cartridge filtration (MILLIPORE) to afford a crude chitinase solution $(100 \mu \mathrm{l})$, which was subjected to $10 \%$ SDS-PAGE. After SDS-PAGE, proteins on the gel 
were transferred to a polyvinylidene difluoride (PVDF) membrane (Clear Blot Membrane-p, ATTO) by electroelution at $100 \mathrm{~mA}$ for 63 minutes (per $85 \times 90 \mathrm{~mm}$ membrane) with three transfer buffers $(300 \mathrm{mM}$ Tris containing $2 \%$ methanol and $0.05 \%$ SDS, $25 \mathrm{mM}$ Tris containing $2 \%$ methanol and $0.05 \%$ SDS, and $25 \mathrm{mM}$ Tris containing $40 \mathrm{mM}$ 6-aminohexanoic acid, 2\% methanol and $0.05 \%$ SDS). The PVDF membrane was stained with $0.2 \%$ Coomassie Brilliant Blue (CBB) R-250 in methanol for 5 minutes and bleached in 50\% methanol containing $10 \%$ acetic acid for several minutes. Each band to be analyzed was cut from the membrane and subjected to the $N$-terminal amino acid sequencing with a protein sequencer (Model 492HT, Applied Biosystems), affording the sequences of $65 \mathrm{kDa}$ protein (ATSATASFVKKSDWGSGFE), $52 \mathrm{kDa}$ protein (GGSVPGDNAPSAPGTP), $47 \mathrm{kDa}$ (AVTDTSAKLSWTAATD), $46 \mathrm{kDa}$ protein (GGGGNPDPGTGGKVNLGYFTD) and $105 \mathrm{kDa}$ protein (GGGGNPDP).

\section{Cloning of chi65 and the 5' Upstream Region of chi65}

A DNA fragment encoding a part of the $N$-terminal amino acid sequence was obtained by PCR with the genomic DNA of strain AJ9463 and degenerate oligonucleotide primers (F1, 5'-TCCGCCACSGCSTCSTTYGT-3'; R1, 5'-TCGAAGGTCAASCCCCARTC-3'), which were designed based on $N$-terminal amino acid sequence of $65 \mathrm{kDa}$ chitinase above mentioned. The $5^{\prime}$ and $3^{\prime}$-flanking regions of the DNA fragment obtained were amplified with the Genome Walker genomic libraries of strain AJ9463 (Genome Walker Kit; CLONTECH) by two consecutive rounds of PCR using the adaptor primers (AP1, 5'-GTAATACGACTCACTATAGGGC-3', and AP2, 5'-ACTATAGGGCACGCGTGGT-3') and two primers (jf1, 5'-GCCACSGCGTCGTTYGTCAAGAA-3', and jf2, 5'-GCGTCGTTYGTCAAGAAGTCCGA-3', for the nucleotide sequence of the $3^{\prime}$-flanking region with a stop codon for chi65; gsp-r1, 5'-CGGAGGGGAAGTCCCACTCGAT-3', and gsp-r2, 5' -CGGTGGTGCCGGTGTTCTTCA-3' for the nucleotide sequence of the 5'flanking region with chi65R and a part of chi65S; sq-r11, 5'-GGTGATCCCGACCGTGAT-3', and sq-r12, 5' -CCCGACCGTGATCAGGAA-3', for the nucleotide sequence of the remaining part of chi65S; chi65SU1-r, 5'-CACGGGCTCGCCGCGGTCTACAT-3', and chi65SU2-r, 5'-GCTCGGCCACTCCACGATCCGCT-3', for the nucleotide sequence of the $5^{\prime}$-upstream region of chi65S.

\section{Nucleotide Sequencing}

Amplified cDNA was ligated into a pCR 2.1 vector (Invitrogen), which was transformed into INV $\alpha F^{\prime}$ cells (Invitrogen) according to the manufacturer's procedure. Plasmid DNAs extracted by a QIAprep Spin Plasmid
Purification kit (QIAGEN) were used for the sequencing with a cycle sequence kit (Thermo Sequence Cy 5.5 dye terminator cycle sequence kit, Amersham Pharmacia Biotech). Nucleotide sequence analyses were carried out on a DNA sequencer (Long-Read Tower DNA sequencer, Amersham Phamacia Biotech, or ABI PRISM ${ }^{\mathrm{TM}} 310$ Genetic Analyzer, PE Biosystems).

\section{Allosamidin Release from Mycelia}

The preculture $(2.0 \mathrm{ml})$ of strain AJ9463 described above was inoculated into a Bennet medium $(100 \mathrm{ml})$ in a $500-\mathrm{ml}$ Erlenmeyer flask, and incubation was done at $30^{\circ} \mathrm{C}$ and $150 \mathrm{rpm}$ on a rotary shaker for 120 hours. Mycelia was collected by centrifugation $(3,000 \mathrm{~g}, 5$ minutes) and washed with distilled water three times. The washed mycelia containing allosamidin $(0.7 \mu \mathrm{g})$ was resuspended in an inorganic salt solution $(50 \mathrm{ml})$ consisting of $\mathrm{KCl} 0.05 \%$, $\mathrm{K}_{2} \mathrm{HPO}_{4} 0.1 \%, \mathrm{MgSO}_{4} \cdot 7 \mathrm{H}_{2} \mathrm{O} 0.05 \%, \mathrm{FeSO}_{4} \cdot 7 \mathrm{H}_{2} \mathrm{O} 0.001 \%$, $\left(\mathrm{NH}_{4}\right)_{2} \mathrm{SO}_{4} 0.2 \%$, $\mathrm{pH} 7.2$, or in a chitin medium $(50 \mathrm{ml})$, and the suspension was incubated at $30^{\circ} \mathrm{C}$ and $150 \mathrm{rpm}$ on a rotary shaker for 24 hours. The amounts of allosamidin in both the mycelia and supernatant were quantified by HPLC [8].

\section{Results}

\section{Effect of Allosamidin on Chitinase Production}

We used an allosamidin-producing strain Streptomyces sp. AJ9463 in this study since the genetic system of the strain has been established [10]. Figure 1 shows dose-response of allosamidin's effect on the chitinase production by strain AJ9463 when the strain was cultured in a chitin medium containing chitin as the sole carbon source. Allosamidin enhanced the chitinase activity of the culture filtrate dosedependently up to $2 \mu \mathrm{M}$ (Fig. 1A). Clear enhancement was observed even at $60 \mathrm{nM}$. The patterns of proteins and chitinases in each culture filtrate were shown in Fig. 1B and $1 \mathrm{C}$, which were detected by silver staining and activity staining after SDS-PAGE, respectively. Two bands at $105 \mathrm{kDa}$ and $46 \mathrm{kDa}$ with chitinase activity were detected in all culture filtrates, and the staining density of both bands increased in a dose-dependent manner. The presence of the two bands in the culture filtrate of a control without allosamidin indicates that they were main chitinases produced by strain AJ9463 in the chitin medium. The two chitinases were inhibited by allosamidin at high concentrations of more than $10 \mu \mathrm{M}$ (Fig. 2).

\section{Growth-promoting Activity of Allosamidin}

In the chitin medium, chitinase production is necessary for 
A

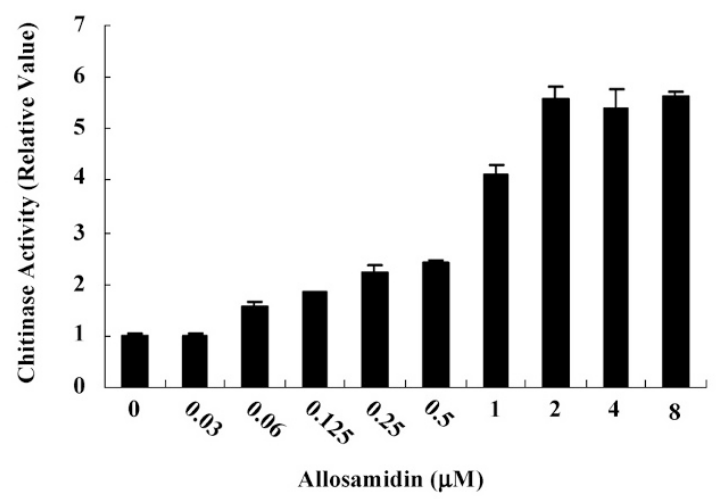

B

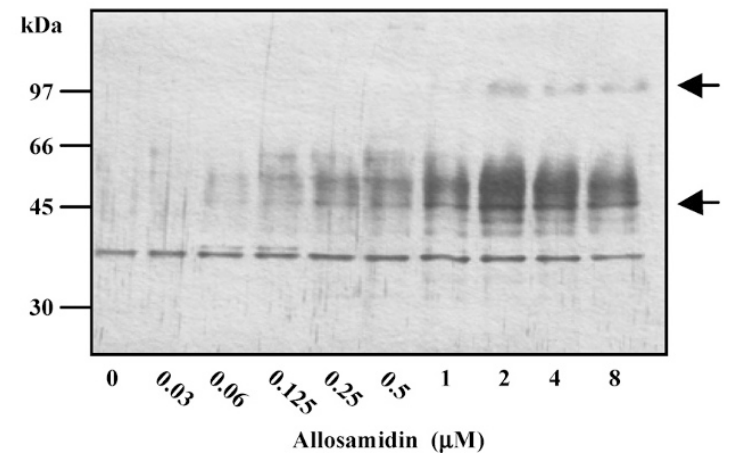

C

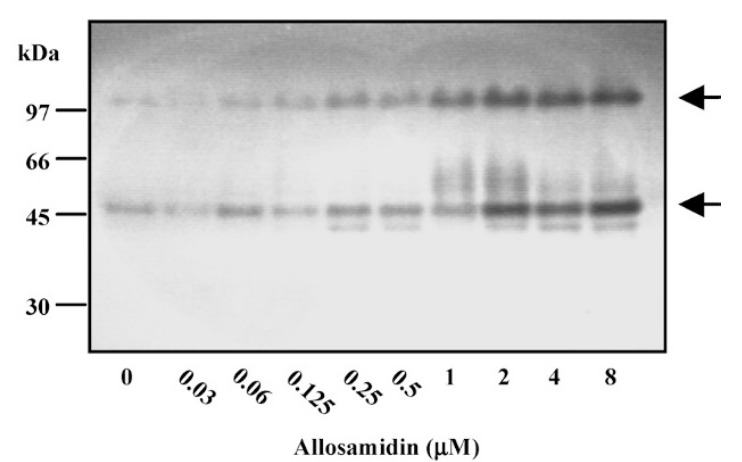

Fig. 1 Effects of allosamidin on chitinase production of Streptomyces sp. AJ9463.

Chitinase activity of the culture filtrate after 24 hours of cultivation in a chitin medium with allosamidin was measured with 4methylumbelliferyl- $N, N^{\prime}, N^{\prime \prime}$-triacetyl chitotrioside $\left[4 \mathrm{MU}-(\mathrm{Gl} / \mathrm{CNAc})_{3}\right]$ as a substrate (A). Proteins and chitinases in each culture filtrate were analyzed by silver staining (B) and activity staining (C). In (A), the values of relative chitinase activity were calibrated based on the activity of a control without allosamidin and means \pm S. E. were shown $(N=3)$. Arrows in $(B)$ and $(C)$ indicate the bands of $105 \mathrm{kDa}$ and $46 \mathrm{kDa}$ proteins.

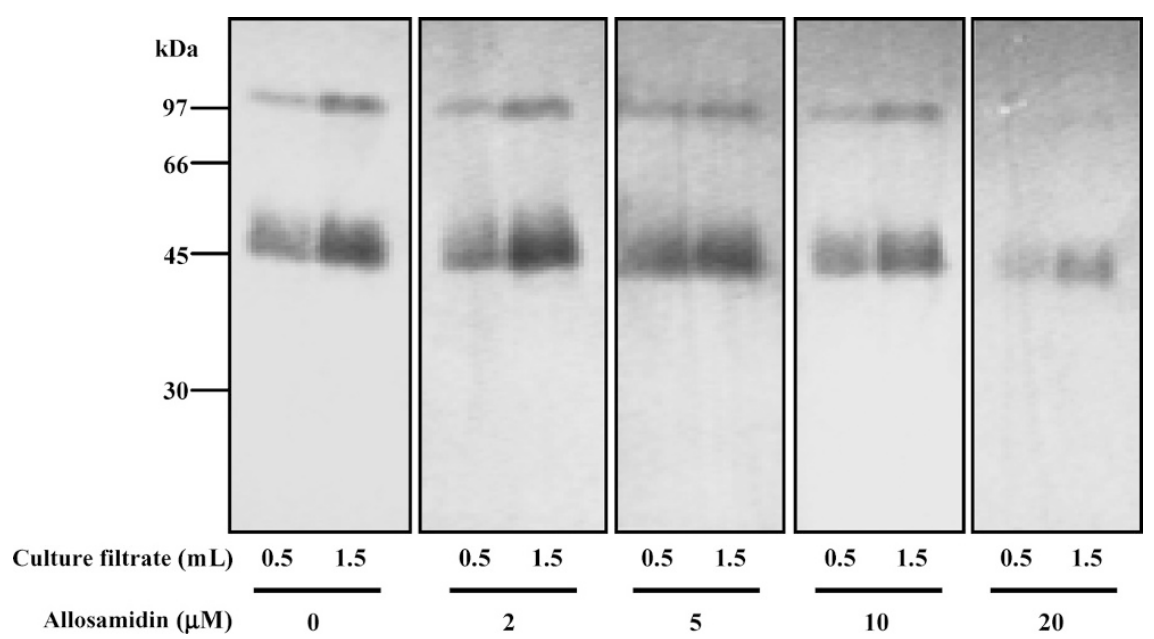

Fig. 2 Inhibition of $46 \mathrm{kDa}$ and $105 \mathrm{kDa}$ chitinase by allosamidin.

After cultivation of strain AJ9463 in a chitin medium for 24 hours, chitinase activity of the culture filtrate $(0.5$ or $1.5 \mathrm{ml})$ obtained was detected by activity staining using the chitin- and allosamidin $(0 \sim 20 \mu \mathrm{M})$-containing gel. 

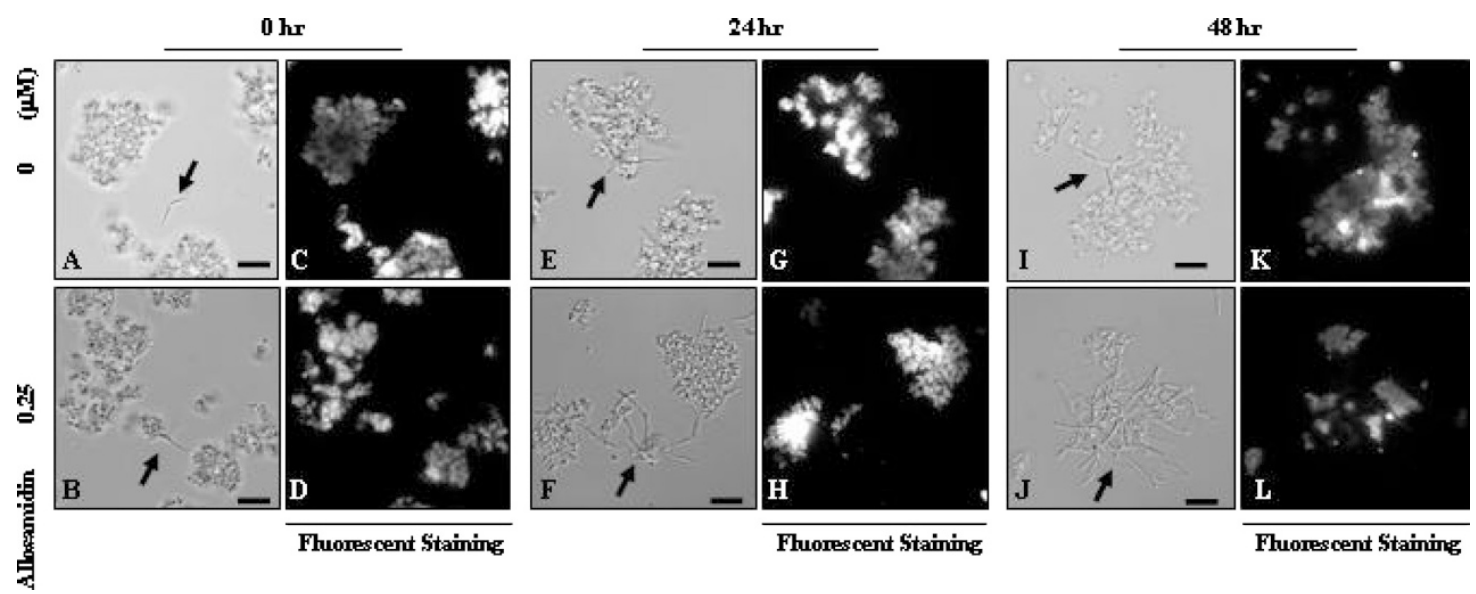

Fig. 3 Growth-promoting activity of allosamidin.

Strain AJ9463 was cultured in a chitin medium with (B, D, F, H, J and L) or without allosamidin (A, C, E, G, I and K) for 0 hour (A, B, C and $D), 24$ hours $(E, F, G$ and $H$ ) or 48 hours $(I, J, K$ and $L)$. Each pair of $A$ and $C, B$ and $D, E$ and $G, F$ and $H, I$ and $K$, or $J$ and $L$ is the same preparation. Mycelia, which are indicated by arrows, and chitin particles in each culture broth were observed under a microscope $(A, B$, E, $F$, I and $\mathrm{J}$ ) and a fluorescence microscope by Calcoflour staining for detection of chitin (C, D, G, H, K and L), respectively. The pattern shown in each photograph was observed over the corresponding culture broth. Scale bar, $10 \mu \mathrm{m}$.

bacterial growth, and the enhancement of chitinase activity would lead to promoting the growth by accelerating chitin degradation. In fact, mycelia of strain AJ9463 grew much better in the presence of allosamidin compared to those of a control without allosamidin as shown in Fig. 3. At that time, the amount of chitin particles remaining in each culture broth, which was shown by Calcoflour staining (Fig. 3 ), indicated that chitin in the culture broth with allosamidin was degraded faster than that in the control culture. ATP levels in culture broths with or without allosamidin were also measured (Fig. 4), which supported the growth-promoting effect of allosamidin. The activation of chitinase production by allosamidin and subsequent growth promotion may synergistically increase the chitinase activity in the culture filtrate as shown in Fig. 1.

\section{Identification of the Chitinase Whose Production Is Promoted by Allosamidin}

When strain AJ9463 was cultured under previously used condition, the pattern of proteins produced in the culture filtrate was different from that under the condition used for experiments in Fig. 1 (1B and 5A). The strength of four bands at $105,65,52$ and $47 \mathrm{kDa}$ on SDS-PAGE of the culture filtrate obtained under the previous condition was mainly enhanced by addition of allosamidin (Fig. 5A). Among them, chitinase activity was detected at 105, 65 and $52 \mathrm{kDa}$ bands by activity staining (Fig. 5B). We first analyzed the $N$-terminal amino acid sequence of the $65 \mathrm{kDa}$ protein after purification of the crude culture filtrate with a chitin column as shown in Fig. 6 and obtained the gene

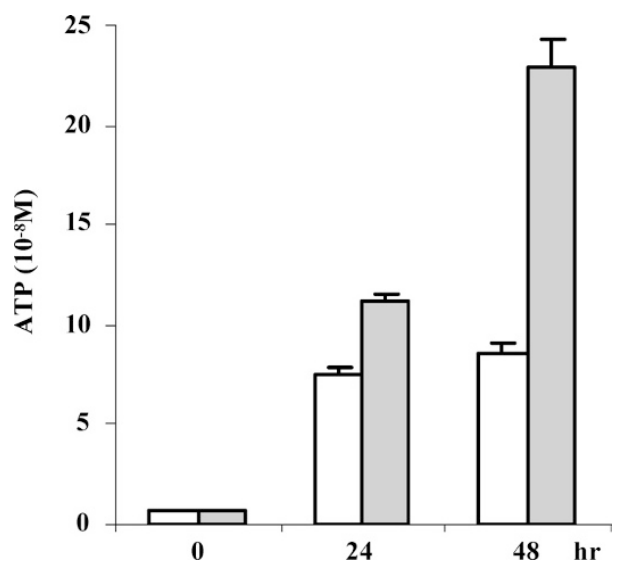

Fig. 4 Growth-promoting activity of allosamidin estimated from ATP amounts.

Strain AJ9463 was cultured in a chitin medium with (gray bars) or without (white bars) allosamidin $(0.25 \mu \mathrm{M})$. ATP amount in each culture broth at 0,24 or 48 hours cultivation time was measured with a luciferin-based bioluminescence assay kit.

encoding it, named chi65 (AB239767), based on the sequence. The amino acid sequence deduced from the nucleotide sequence of chi65 had high homology to known family 18 chitinases of Streptomyces such as chitinase 63 of $S$. plicatus, chitinase C of $S$. coelicolor and chitinase C of $S$. lividans [11]. Further analysis of the $N$-terminal amino acid sequences of 52 and $47 \mathrm{kDa}$ proteins in Fig. 5A and $46 \mathrm{kDa}$ protein in Fig. 1B showed that these three proteins also originated from the same gene, chi65. The $\mathrm{N}$ terminal positions of these proteins are schematically 
shown in Fig. 7. Analysis of the $\mathrm{N}$-terminal amino acid sequence of $105 \mathrm{kDa}$ protein revealed that the protein also originated from chi65, suggesting a dimer structure of $105 \mathrm{kDa}$ protein.

A DNA fragment containing chi65 was obtained and its nucleotide sequence revealed the presence of two genes, named chi65S and chi65R (AB239767), at the 5'-upstream region of chi65. The amino acid sequences deduced from the nucleotide sequences of the genes indicated that chi65S and chi65R encoded a sensor histidine kinase and a response regulator, respectively, constructing a typical twocomponent regulatory system.

\section{Allosamidin Release from the Mycelia by Responding to Chitin}

In all allosamidin-producing strains we isolated, most of the allosamidin produced has been obtained from mycelia cultured in a chitin-free medium such as a Bennet medium [12]. To know the mechanism of allosamidin transfer among cells, its localization in the culture broth was investigated with the chitin medium. Strain AJ9463 was

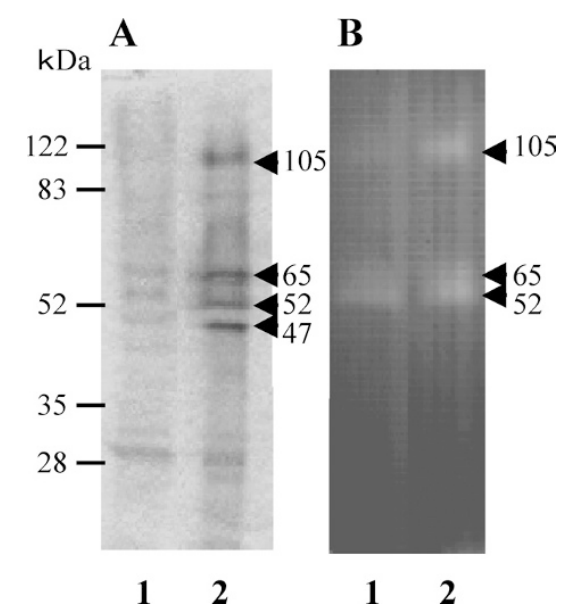

Fig. 5 The pattern of proteins produced by strain AJ9463 under the culture conditions previously used.

Proteins and chitinase activity of the culture filtrate after 24 hours cultivation in a chitin medium with (lane 2) or without (lane 1) allosamidin $(2 \mu \mathrm{M})$ were detected by CBB staining after SDS-PAGE (A) and by activity staining on chitin-containing gel (B), respectively. cultured in a Bennet medium to obtain the mycelia which contained allosamidin. When the mycelia were collected and shaken in an inorganic salt solution, most of the allosamidin was maintained in the mycelia after incubation (Fig. 8). However, more than $80 \%$ of the allosamidin was recovered from the culture filtrate when the mycelia were incubated in the chitin medium. In the chitin medium, allosamidin production by strain AJ9463 starts at around 72 hours of cultivation and reaches a few hundred $\mathrm{nM}$ in the culture filtrate after 120 hours of cultivation.

\section{Discussion}

The variety of secondary metabolisms present in microorganisms suggests that they have been developing them during evolution and each secondary metabolite might have a significant role in its producer under
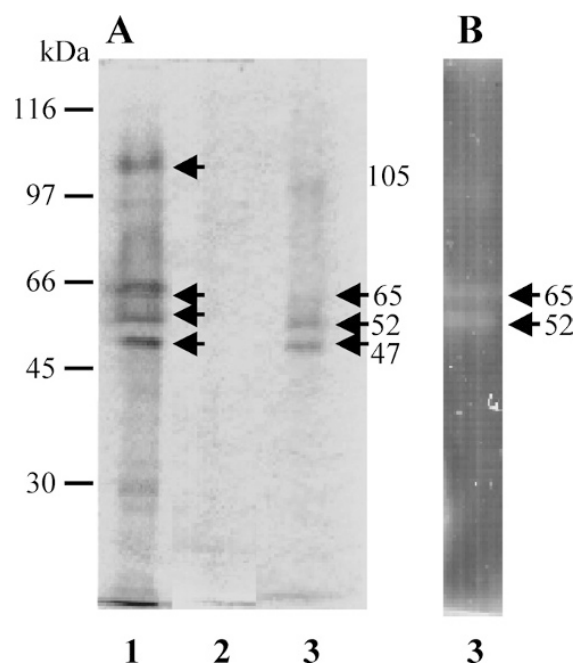

Fig. 6 Partial purification of chitinases by chitin column.

Culture filtrate after 24 cultivation in a chitin medium with allosamidin $(2 \mu \mathrm{M})$ was absorbed on a chitin column and eluted with $50 \mathrm{mM}$ Tris- $\mathrm{HCl}(\mathrm{pH}$ 9.0) and $100 \mathrm{mM}$ acetic acid $(\mathrm{pH} 3.0)$ successively. Each fraction (lane 1, culture filtrate; lane 2, $50 \mathrm{mM}$ Tris- $\mathrm{HCl}$ eluate; lane 3, $100 \mathrm{mM}$ acetic acid eluate) was electrophoresed and stained by CBB (A). Chitinase activity of the $100 \mathrm{mM}$ acetic acid fraction was detected by activity staining (B).

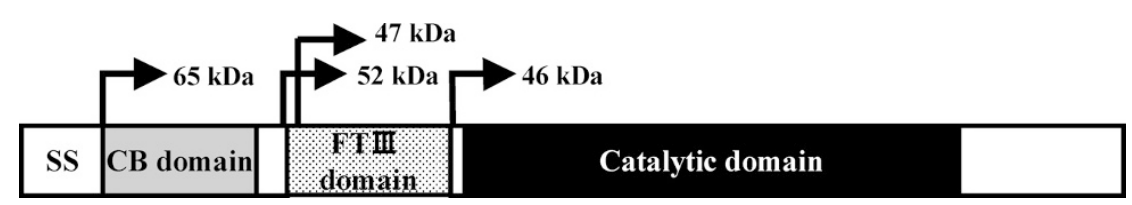

Fig. 7 Schematic representation of chitinases encoded by chi65.

Positions of $\mathrm{N}$-terminal residue of $65,52,47$ and $46 \mathrm{kDa}$ proteins are indicated by solid arrows. SS, signal sequence; CB domain, chitinbinding domain; FT III domain, fibronectin type III domain. 


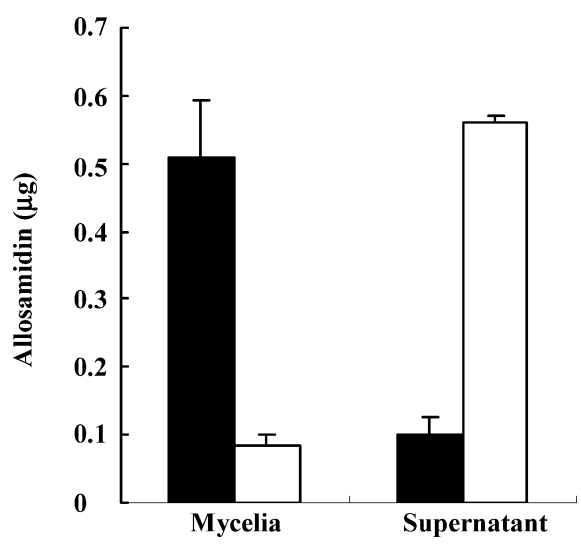

Fig. 8 Allosamidin release from mycelia.

Strain AJ9463 was cultured in a Bennet medium to obtain mycelia containing allosamidin $(0.7 \mu \mathrm{g})$, which were incubated in an inorganic salt solution (black bars) or in a chitin medium (white bars). After 24 hours of incubation, the amounts of allosamidin in both the mycelia and supernatant were quantified by HPLC. Means $\pm S$.E. were shown $(\mathrm{N}=3)$.

some circumstances. The role of antibiotic production is presumable but has not been proved. It is entirely unknown why microorganisms produce many other compounds without antibiotic activity such as enzyme inhibitors. In this study, to present a model of a physiological role of a microbial secondary metabolite, we focused on action of the chitinase inhibitor allosamidin on chitinase production in its producing Streptomyces.

Allosamidin can strongly enhance the chitinase production of strain AJ9463 dose-dependently up to a few $\mu \mathrm{M}$. The effective concentration of allosamidin on chitinase production may be physiologically significant because the concentration of allosamidin produced in the culture broth was usually around the range of a few hundred $\mathrm{nM}$ to a few $\mu \mathrm{M}[12]$. Moreover the fact that the enzymatic activity of the chitinase whose production is enhanced by allosamidin was not inhibited under the presence of a few $\mu \mathrm{M}$ of allosamidin suggests that the allosamidin's effect on chitinase production is not disturbed by its chitinase inhibitory activity at low concentrations effective on chitinase production.

In many cases, Streptomyces chitinase has been found in the culture broth as a degradation product of a protein encoded by a chitinase gene [11, 13]. Furthermore, some cases are known that multiple degradation proteins with chitinase activity are formed from a chitinase protein [14]. Therefore, multiplicity of chitinase proteins detected in the culture filtrate of strain AJ9463 is not an extraordinary case although it is not clear why the degradation pattern was different between two culture conditions. The fact that all chitinases mainly produced in the chitin medium originated from a gene chi65 may indicate importance of the chitinase gene for growth of the strain in chitin-rich environment.

In the two-component regulatory system of CHI65S and CHI65R, a signal molecule existing outside of the cells may attach the sensor moiety of CHI65S, a membrane protein with five membrane-spanning domains, and the signal may activate CHI65R, a DNA binding protein with a helix-turn-helix domain, by a phosphorylation relay system observed in usual two-component regulatory systems [15]. The activated CHI65R would regulate chi65 expression. Many chitinase genes of Streptomyces have been obtained, but in only two cases, chi40 of S. thermoviolaceus [16] and chiC of S. coelicolor [17], homologs of chi65S and chi65R are present in the upstream region of each chitinase gene. Although S. lividans transformed with a DNA fragment containing chi40 and two genes encoding the twocomponent system could produce CHI40 in the presence of chitin and a gene disruption experiment suggested that the two-component system may regulate the chiC expression in $S$. coelicolor, detailed mechanism for the regulation including a ligand of the sensor moiety has not been clarified in both cases.

We found a novel phenomenon that allosamidin is released from the mycelia when chitin is present in a medium. This indicates that chitin or some other factors such as degradation products of chitin can release allosamidin from the mycelia, which is very important for allosamidin's action as a signal molecule and may validate our experiments in which allosamidin was added exogenously into the chitin medium.

From this study, we can imagine the following physiological role of allosamidin in its producing Streptomyces. Since the growing phase of mycelia in Streptomyces is not synchronized, allosamidin production would start in some part of mycelia at the middle growing phase [12]. The allosamidin produced would be released to the outside of the mycelia in the presence of chitin and transported to any part of mycelia in the allosamidinproducing strain itself or other allosamidin-producing strains. It would activate the chitinase production through the two-component regulatory system, which would further promote growth of the allosamidin-producing strains in a chitin-rich environment. This is a novel model demonstrating that a secondary metabolite of Streptomyces with a specific biological activity shows clear physiological activity toward its producer. Studies to investigate the mechanism for regulation of chitinase production by allosamidin through a two-component regulatory system are described in the following paper. 
Acknowledgments We are grateful to K. Miyashita and T. Araki for generous experimental advice and to S. Nagata for helpful discussion. This work was supported by grants from the Waksman Foundation of Japan, the Sapporo Bioscience Foundation and the Japan Society for the Promotion of Science.

\section{References}

1. Sakuda S, Isogai A, Matsumoto S, Suzuki A. Search for microbial insect growth regulators II. Allosamidin, a novel insect chitinase inhibitor. J Antibiot 40: 296-300 (1987)

2. Sakuda S, Isogai A, Matsumoto S, Suzuki A, Koseki K. Structure of allosamisin, a novel insect chitinase inhibitor, produced by Streptomyces sp. Tetrahedron Lett 27: 24752478 (1986)

3. Henrissat BA. Classification of glycosyl hydrolases based on amino acid sequence similarities. Biochem J 280: 309-316 (1991)

4. Sakuda S, Nishimoto Y, Ohi M, Watanabe M, Takayama S, Isogai A, Yamada Y. Effects of demethylallosamidin, a potent yeast chitinase inhibitor, on the cell division of yeast. Agric Biol Chem 54: 1333-1335 (1990)

5. Vinetz JM, Dave SK, Specht CA, Brameld KA, Xu B, Hayward R, Fidock DA. The chitinase pfCHT1 from the human malaria parasite Plasmodium faciparum lacks proenzyme and chitin-binding domains and displays unique substrate preferences. Proc Natl Acad Sci USA 96: 1406114066 (1999)

6. Zhu Z, Zheng T, Homer RJ, Kim YK, Chen NY, Cohn L, Hamid Q, Elias JA. Acidic mammalian chitinase in asthmatic Th2 inflammation and IL-13 pathway activation. Science 304: 1678-1682 (2004)

7. Nakanishi E, Okamoto S, Matsuura H, Nagasawa $H$, Sakuda S. Allosamidin, a chitinase inhibitor produced by Streptomyces, acts as an inducer of chitinase production in its producing strain. Proc Japan Academy, Ser B 77: 79-82 (2001)

8. Zhou Z, Sakuda S, Yamada Y. Biosynthetic studies on the chitinase inhibitor, allosamidin. Origin of the carbon and nitrogen atoms. J Chem Soc Perkin Trans 1: 1649-1652 (1992)

9. Kuranda MJ, Robbins PW. Chitinase is required for cell separation during growth of Saccharomyces cerevisiae. J Biol Chem 266: 19758-19767 (1991)

10. Kawachi R, Koike Y, Watanabe Y, Nishio T, Sakuda S, Nagasawa H, Oku T. Development of a genetic system in chitinase-producing Streptomyces and the application of an allosamidin-insensitive chitinase gene to homologous overexpression. Mol Biotechnol 26: 179-186 (2004)

11. Kawase T, Kanai R, Ohno T, Tanabe T, Nikaidou N, Miyashita K, Mitsutomi M, Watanabe T. Identification of three family 18 chitinase genes of Streptomyces griseus HUT6037. Chitin and Chitosan Research 7: 241-251 (2001)

12. Wang Q, Zhou Z, Sakuda S, Yamada Y. Purification of allosamidin-sensitive and -insensitive chitinases produced by allosamidin-producing Streptomyces. Biosci Biotech Biochem 57: 467-470 (1993)

13. Vetrivel KS, Pandian SK, Chaudhary U, Dharmalingam K. Purification, cloning, and DNA sequence analysis of a chitinase from an overproducing mutant of Streptomyces peucetius defective in daunorubicin biosynthesis. Can J Microbiol 47: 179-187 (2001)

14. Romaguera A, Menge U, Breves R, Diekmann H. Chitinases of Streptomyces olivaceoviridis and significance of processing for multiplicity. J Bacteriol 174: 3450-3454 (1992)

15. Hutchings MI, Hoskisson PA, Chandra G, Buttner MJ. Sensing and responding to diverse extracellular signals? Analysis of the sensor kinases and response regulators of Streptomyces coelicolor A3(2). Microbiology 150: 2795-2806 (2004)

16. Tsujibo H, Hatano N, Okamoto T, Endo H, Miyamoto K, Inamori Y. Synthesis of chitinase in Streptomyces thermoviolaceus is regulated by a two-component sensorregulator system. FEMS Microbiol Lett 181: 83-90 (1999)

17. Homerova D, Knirschova R, Kormanec J. Response regulator ChiR regulates expression of chitinase gene, chic, in Streptomyces coelicolor. Folia Microbiol 47: 499-505 (2002) 